\title{
Influence of Agricultural Residue Ash on Early Cement Hydration and Chemical Admixtures Adsorption
}

\author{
Feraidon F. Ataie and Kyle A. Riding \\ Corresponding author's email: fataie@csuchico.edu
}

\begin{abstract}
:
This study investigated impacts of internal surface area of wheat straw ash (WSA) and rice straw ash (RSA) on cement early hydration as well as on chemical admixture adsorption in cementitious systems. Results were compared to those of silica fume. Hydration kinetics and mortar strength experiments showed RSA and WSA to have similar reactivity to silica fume. High surface areas of WSA and RSA did not increase early hydration as compared to silica fume. However, high surface areas of WSA and RSA dramatically increased their adsorption capacity of air entraining agents and retarders compared to silica fume.
\end{abstract}




\section{Introduction:}

Supplementary cementitious materials (SCMs) particularly industrial by-products such as

22 fly ash, silica fume, and slag, are widely used to partially replace portland cement in concrete to

23 reduce carbon footprint and increase quality of concrete. However, these materials are not

24 available in large quantities at a low cost uniformly around the world. Natural SCMs such as

25 agricultural residue ash (ARA) are gaining more attention for use as SCMs because of their low

26 cost, wide availability, and excellent reactivity in concrete. Every year, millions of tonnes of

27 agricultural residues such as corn stover, wheat straw, and rice straw are produced worldwide

28 [1]. Some biofuel plants are beginning to produce thousand tonnes of biomass waste material

29 that would otherwise be landfilled. After burning, the ash is very friable and requires only

30 minimal energy to grind [2]. Therefore, agricultural residues are renewable and sustainable

31 resources for ARA production for concrete use. Because ARAs, such as Rice Straw Ash (RSA)

32 and Wheat Straw Ash (WSA), can be produced at low cost, they are of great interest to the

33 concrete industry, especially in developing regions.

34 Chemical and physical properties of ARA depend on the type of agricultural residue. This

35 is because each of agricultural residues, such as rice straw, wheat straw, and corn stover, has

36 different composition. The composition of agricultural residues greatly affects the burning

37 sensitivity of ARA, and influences the suitability of ARA for use in concrete [2] [3] [4].

38 However, variability of ARAs and their sensitivity to burning conditions can greatly be reduced

39 by using pretreatment techniques, such as dilute acid pretreatment [2] [3]. Using pretreatment

40 methods, ARA can be made with a high surface area and high amorphous silica content, making

41 them highly reactive pozzolanic materials [2] [5] [3] [6] [7]. More research is needed to study

42 whether pretreatment techniques are economically as well as environmentally feasible for SCMs 
43 production or not. However, biofuel industry produces a lignocellulosic waste product that is

44 equivalent to pretreated agricultural residues; authors have shown that the waste product could

45 be used to produce highly reactive SCMs without any pretreatment [2].

46 It has been shown that pretreated WSA and RSA have enhanced pozzolanic reaction [3].

47 The pozzolanic reaction is the reaction between a siliceous material and calcium hydroxide $(\mathrm{CH})$

48 under water to form a cementitious material, as shown in Eq. 1( [8])

$$
\mathrm{CH}+\mathrm{S}+\mathrm{H} \rightarrow \mathrm{CSH} \quad \text { Eq. } 1
$$

49 Note: Oxide notation is used throughout this paper, $\mathrm{C}=\mathrm{CaO}, \mathrm{S}=\mathrm{SiO}_{2}, \mathrm{H}=\mathrm{H}_{2} \mathrm{O}, \mathrm{A}=\mathrm{Al}_{2} \mathrm{O}_{3}$, $50 \quad \mathrm{~F}=\mathrm{Fe}_{2} \mathrm{O}_{3}$.

The pozzolanic reaction is known to be affected by many factors such as mineralogy,

52 surface area, and carbon content of the pozzolanic materials. Being one of the most reactive

53 pozzolanic materials, silica fume has high amorphous silica content and relatively high surface

54 area. Surface area and amorphous silica content are the two most influential factors in pozzolanic

55 reaction. Surface area of SCMs has a major impact on the reaction rate. Surface area provides

56 nucleation sites for calcium silicate hydrate $(\mathrm{C}-\mathrm{S}-\mathrm{H})$ precipitation which plays an essential role in

57 the hydration process of cementitious systems [9]. However, an increase in surface area of SCMs

58 could increase adsorption of chemical admixtures, such as air entraining agents (AEAs) and

59 superplasticizers [10] [11] [12]. Using foam index method, Ley et al. [10] suggested that as the

60 surface area of fly ash samples increases the demand of concrete containing fly ash to AEA

61 becomes higher.

62 Authors have published other publications focusing on methods and techniques to 63 enhanced pozzolanic reactivity of ARAs, namely WSA, and RSA [2, 3, 4]. This study, however, 64 emphasizes on the impact(s) of ARAs properties, particularly their surface area, on concrete 65 chemical admixtures. Although ARAs, particularly WSA and RSA, can have similar chemical 
66 compositions to those of the silica fume, they can have higher surface area than silica fume [3].

67 Contrarily to the relatively spherical particle shapes found with silica fume, ARAs contain

68 porous and irregularly shaped particles. The high surface area of ARAs has been attributed to

69 their internal porosity [7]. Because most of the ARAs surface area is attributed to their internal

70 porosity, the ability of ARAs in adsorbing chemical admixtures in cementitious systems has not

71 been established yet. Furthermore, the impact of internal surface area on the early cement

72 hydration has not been investigated yet. The impact of internal surface area on the cement

73 hydration and adsorption could be different than that of the external surface area. Internal

74 porosities of ARAs, as reactive pozzolanic materials with high amorphous silica content, could

75 be blocked by hydration products. It is also possible that dissolution of ARAs in cementitious

76 system will rapidly reduce their surface area. Both of these phenomena, blockage and dissolution

77 of surface area, could reduce ARAs pozzolanic reaction rate and ability to adsorb chemical

78 admixtures in cementitious systems.

79 This study aimed to investigate the impact of ARA surface area on the early cement

80 hydration and on the adsorption of chemical admixtures in cementitious systems. WSA and RSA

81 with high surface area and amorphous content was produced. Additionally, because WSA and

82 RSA had similar chemical compositions to that of silica fume, an undensified silica fume sample

83 was selected for comparison. Undensified silica fume rather than densified silica fume was

84 selected to provide improved dispersion. Pozzolanic behavior of WSA, RSA, and silica fume

85 was determined by measuring the impact of each material on heat of hydration, calcium

86 hydroxide $(\mathrm{CH})$ consumption, and chemical shrinkage of paste samples, and compressive

87 strength of mortar cubes. The Chappelle test [13] was also used as an index test for material 
88 pozzolanic reactivity with calcium hydroxide solution. WSA and RSA adsorption capacity of

89 chemical admixtures was tested on air entraining agents and cement hydration retarders.

\section{2. Materials and methods:}

\section{2.1. Materials:}

93 this study. Cement and silica fume chemical and physical properties are shown in Table 1 and

94 Table 2, respectively. Standard graded sand [15] was used for the mortar experiments. Wheat

95 straw (WS) was purchased from a local farm in Manhattan, Kansas, and rice straw (RS) was

96 obtained from Missouri Rice Research Farm, Glennonville, Missouri. A reagent grade $\mathrm{HCl}$ was

97 obtained and diluted to $0.1 \mathrm{~N}$ for use in the study. Reagent grade calcium oxide (CaO) and ACS

98 grade zinc oxide were used for Chappelle test and Rietveld analysis, respectively. A high-grade

99 saponified rosin air entraining admixture was used. An aqueous solution of hydroxylated organic

100 compounds was employed as cement hydration retarder.

\section{2.2. Methods:}

\section{$102 \quad$ 2.2.1. Biomass ash preparation:}

It has been shown that removal of alkalis and organic compounds from biomass prior to

104 burning (ashing) can dramatically enhance pozzolanic properties of biomass ash [2] [3]. In this

105 study, the biomass (wheat straw and rice straw) was pretreated with $0.1 \mathrm{~N} \mathrm{HCl}$ at $80^{\circ} \mathrm{C}$ to remove

106 impurities from biomass in order to produce WSA and RSA with high amorphous content, high

107 surface area, and low loss on ignition (LOI). To pretreat the biomass, $250 \mathrm{~g}$ of biomass (rice

108 straw or wheat straw) was immersed in $3100 \pm 100 \mathrm{~mL}$ of $0.1 \mathrm{~N} \mathrm{HCl}$ solution in a $4000 \mathrm{~mL}$ glass

109 jar. The sample was stored undisturbed at a constant temperature of $80^{\circ} \mathrm{C}$ for $24 \mathrm{hrs}$. The biomass

110 was then rinsed twice, each time with $2500 \mathrm{~mL}$ of distilled water, and dried at $80^{\circ} \mathrm{C}$ in an oven. 
111 To prepare the ash (WSA or RSA), a programmable electric muffle furnace was used to heat the

112 biomass. $200 \mathrm{~g}$ of dried biomass was ashed in each batch. A stainless steel cage with two wire

113 mesh shelves was used to hold the biomass during burning, and a stainless steel pan was placed

114 below the cage to catch any ash that fell through the mesh. It took the furnace an hour to reach to

$115650^{\circ} \mathrm{C}$ and almost 6 hours to cool down to room temperature. It is worth mentioning that the

116 biomass was first placed in the furnace and then the furnace was turned on. Finally, the ash was

117 ground for one hour at 85 revolutions per minute $(\mathrm{rpm})$ in a laboratory ball mill. WSA was

118 prepared by burning the pretreated wheat straw at $650^{\circ} \mathrm{C}$ for one hour and was called (WSA650).

119 Two types of RSA were prepared. (RSA650) was obtained by burning pretreated rice straw at

$120650^{\circ} \mathrm{C}$ for one hour, and (RSA500) was prepared by burning pretreated rice straw at $500^{\circ} \mathrm{C}$ for

121 two hours. Properties of WSA and RSA are shown in Table 2.

122 2.2.2. Silica fume and biomass ash characterization:

123 Physical and chemical characteristics (such as particle size, surface area, and amorphous

124 content) of SCMs affect their behavior in cementitious systems. Particle size and surface area are

125 influential factors on early pozzolanic reaction of SCMs [9]. Beside packing effect, particle size

126 distribution influences the pozzolanic reaction; the finer the particle size of SCMs, the faster

127 their pozzolanic reaction [16]. Surface area has been shown to largely impact the pozzolanic

128 reaction of SCMs. An increase in surface area could enhance the pozzolanic reaction; it also

129 increases the potential of chemical admixture absorption [10]. It is also well established that an

130 increase in amorphous silica content is associated with an increase in pozzolanic reaction.

131 In this study, particle-size distribution silica fume, WSA, and RSA samples were

132 determined using a laser diffractometer. Ultrasonic waves were used to disperse the particles in

133 an isopropanol suspension during the laser diffraction particle size measurements. Surface area 
134 was measured using BET nitrogen adsorption. LOI was determined by measuring mass loss

135 after heating one gram of dry materials (SF, WSA or RSA) to $900^{\circ} \mathrm{C}$ for three hrs. Chemical

136 composition of ash samples and silica fume was determined using x-ray fluorescence (XRF).

137 Secondary electron images of selected ash samples were taken using Scanning Electron

138 Microscopy (SEM). Ash samples were carbon coated to reduce surface charging during imaging

139 process to improve quality of images.

140 To determine crystalline phases of the materials, $\mathrm{x}$-ray diffraction (XRD) analysis was

141 performed $(\mathrm{Cu} \mathrm{K} \alpha$ radiation with $\lambda=1.5046 \AA)$. A step size of $0.02^{\circ} 2 \theta / 4 \mathrm{~s}$ and a scan range of $5^{\circ}-$

$14270^{\circ} 2 \theta$ was used. The Rietveld analysis [17] [18] [19] was performed to obtain the amorphous

143 content of the WSA, RSA, and silica fume. Sample preparation for Rietveld refinement analysis

144 included mixing $1.8 \mathrm{~g}$ of SCM with $0.2 \mathrm{~g}$ of zinc oxide as an internal standard in ethanol to create

145 a slurry. This was followed by hand grinding in a ceramic mortar for approximately two min.,

146 followed by drying in a fume hood for $20 \mathrm{~min}$. The Rietveld algorithm optimizes the model

147 function by minimizing the weighted sum of squared difference between observed and computed

148 intensity values [20]. The refinement process of each SCM sample was evaluated with R-factor

149 refinement criteria, including R-pattern (Rp), R-weighted pattern (Rwp) and R-expected (Rexp)

150 [21]. A commercial software was used to perform the Rietveld refinement until the best fit was

151 obtained.

152 2.2.3. Pozzolanic reactivity measurements:

153 Several experimental procedures, such as heat of hydration, chemical shrinkage, and

154 calcium hydroxide consumption measurements, have been used to determine the pozzolanicity of

155 SCMs [9] [22] [23]. Reactive SCMs when added to cementitious systems increase heat of

156 hydration and chemical shrinkage of cementitious systems [24]. However, pozzolanic reaction 
157 between SCMs and cementitious systems reduces the $\mathrm{CH}$ content of the system based on Eq.1. In

158 this study pozzolanic reactivity of WSA, RSA, and silica fume was measured by several

159 experimental methods.

$160 \quad$ Chapelle test [13] was used to determine pozzolanic reactivity of the SCMs by measuring

161 the calcium hydroxide consumption by SCMs in a calcium hydroxide solution. The Chapelle test

162 is a French standard (NF P18-513) [13] and has been used to measure pozzolanic properties of

$163 \mathrm{SCMs}$ [22] [25] [26]. In this test, $2 \mathrm{~g}$ of calcium oxide was mixed with $1 \mathrm{~g}$ of SCM sample in

$164250 \mathrm{~mL}$ of deionized water in a $500 \mathrm{~mL}$ Erlenmeyer glass flask. The flask was placed on a

165 stirring-heating plate for $16 \mathrm{hrs}$ at $90^{\circ} \mathrm{C}$. At the end of $16 \mathrm{hrs}$, the slurry was cooled to $23^{\circ} \mathrm{C}$ by

166 placing the flask in cold water. $60 \mathrm{~g}$ of sucrose was mixed with $250 \mathrm{ml}$ of deionized water, added

167 to the slurry, and stirred for $15 \mathrm{~min}$. The resulting solution was filtered through a $1.1 \mu \mathrm{m}$

168 diameter filter paper. Five drops of $0.1 \%$ phenolphthalein and $25 \mathrm{~mL}$ of filtrate were then titrated

169 with $0.1 \mathrm{~N} \mathrm{HCl}$. The total volume of $0.1 \mathrm{~N} \mathrm{HCl}$ solution needed for titration was recorded as $\mathrm{V}_{\mathrm{b}}$

170 for the blank sample (no WSA, RSA, or silica fume added) and $\mathrm{V}_{\mathrm{m}}$ for samples containing SCMs

171 (WSA, RSA, and silica fume). Titration results were then used to determine the amount of

172 calcium hydroxide (mg) fixed by the pozzolanic materials using Equation 1:

$$
\mathrm{Ca}(\mathrm{OH})_{2} \text { fixed }=2 \frac{\left(V_{b}-V_{m}\right)}{V_{b}} \frac{74}{56} 1000 \quad \text { Eq. } 1
$$

174 Pozzolanic reactivity was also determined by measuring the heat of hydration of cement

175 paste samples containing SCM (WSA, RSA, or silica fume). 10\% cement by weight was

176 replaced with WSA, RSA, or silica fume when used. A 0.45 water-cementitious material ratio

177 (w/cm) was used. Paste samples were mixed with a vertical laboratory mixer [27]. Distilled

178 water was added to the cementitious material and mixed at $500 \mathrm{rpm}$ for 90 seconds, followed by 
a 120 second rest period, and then mixed at $2000 \mathrm{rpm}$ for 120 seconds. Paste samples of approximately $30 \mathrm{~g}$ each were used in an eight-channel isothermal calorimeter at $23^{\circ} \mathrm{C}$.

182 determine $\mathrm{CH}$ reduction by the pozzolanic reaction. To obtain $\mathrm{CH}$ content of paste samples, 183 samples were cast in $11 \mathrm{ml}$ polystyrene vials. Hydration was stopped at 7, 28, and 90 days of 184 hydration by means of solvent exchange with isopropanol. Samples approximately $2 \mathrm{~mm}$ thick 185 were cut and placed in isopropanol for seven days. After this period, the samples were dried in a 186 vacuum for at least three days. $\mathrm{CH}$ content was measured using a thermogravimetric analyzer 187 (TGA) to heat the dried samples at $20^{\circ} \mathrm{C} / \mathrm{min}$ up to $800^{\circ} \mathrm{C}$ in a nitrogen environment [28]. Chemical shrinkage has also been used to determine the pozzolanicity of SCMs [24]. The 189 chemical shrinkage is the total shrinkage resulting from hydration process in paste sample. The 190 chemical shrinkage happens because the volume of reactants (cement and water) is less than the 191 volume occupied by the hydration products [24]. The chemical shrinkage of paste samples were 192 measured in accordance with procedure A of ASTM C1608. Approximately $6 \mathrm{~g}$ of paste sample 193 was cast in a $26 \mathrm{ml}$ polystyrene vial. The vial was then filled with water. A capillary tube was 194 inserted through the center of a rubber stopper, and the stopper was then inserted into the vial. 195 The capillary tube was partially filled by distilled water, and a few drops of red oil were added in 196 the tube. The decrease in water level in the tube was monitored by taking pictures with an 197 automatic webcam. The images taken were then analyzed suing Shrinkage Suite developed by 198 Bishnoi [29]. The average of three replicate samples was used for chemical shrinkage results. 199 Mortar cube compressive strength was also measured to determine the impact of SCMs 200 on compressive strength. This test was performed according to ASTM C 109 [30] with a sand to 201 cementitious material ratio of 2.75 . To keep the w/cm of paste and mortar samples identical, 
w/cm for all mortar samples was also 0.45 . WSA, RSA, or silica fume was used at $10 \%$

203 replacement level by mass of cement. Mortar cube compressive strength was tested at 7, 28, and

20491 days with results reported as the average of three mortar cubes.

\section{2.2.4. Foam Index (FI) test:}

The foam index test has been used to determine AEA adsorption by fly ash and other

207 supplementary cementitious materials (SCMs) in cementitious systems [10] [31]. The test

208 measures AEA adsorption in cementitious slurry and determines the amount of AEA needed to

209 stabilize the foam layer at the top surface of the slurry. In this study, an ASTM sand equivalent

210 shaker was used to ensure consistent shaking from sample to sample [32]. Ten gram of SCM

211 (ash or silica fume) was mixed in $20 \mathrm{~mL}$ of deionized water in a $50 \mathrm{~mL}$ plastic centrifuge tube.

212 The tube had a height of $115 \mathrm{~mm}$ and a diameter of $27 \mathrm{~mm}$. The tube was shaken for $30 \mathrm{sec}$,

213 followed by a 30-second rest period. Twenty $\mu 1$ of 5\% air-entraining agent solution was added to

214 the mixture, and the mixture was shaken for $10 \mathrm{sec}$. The tube was left undisturbed for 15

215 seconds. A shaking speed of 172 cycles per min was used. At this time, if a stable foam layer at

216 the water-air interface was observed, the volume of AEA was recorded as the foam index. If,

217 however, a stable foam layer was absent, another $20 \mu 1$ of 5\% AEA solution was added and the

218 procedure continued until a stable foam layer was reached and recorded. To determine the

219 impact of ash samples on the foam index, $5 \%, 10 \%$, or $20 \%$, of the cement was replaced by the

220 ash with a constant water volume.

\section{2.2.5. Retardation measurements:}

222 Calorimetry experiments were conducted to see the potential impact of nucleation site 223 seeding from the high surface area SCMs on retardation effects from retarder use. To measure 224 the impact of WSA, RSA, and silica fume on retardation, two different cement replacement 
225 levels of $5 \%$ and $10 \%$ were used. Paste samples of approximately $30 \mathrm{~g}$ each were used in an

226 eight-channel isothermal calorimeter at $23^{\circ} \mathrm{C}$ to measure heat of hydration. An aqueous solution

227 of hydroxylated organic compounds was used as the retarder with a dosage of 200ml/100 $\mathrm{kg}$ of

228 cement.

\section{3. Results and Discussion:}

\section{3.1. Materials characteristics:}

Particle size distribution of cement (OPC), WSA, RSA, and silica fume samples is shown

232 in Fig. 1. In spite of the use of undensified silica fume and ultrasonic dispersion, large particle 233 sizes were seen in the particle size distribution. This could be because of agglomeration of silica

234 fume particles or because the majority of silica fume particles were smaller than the size

235 detectable by the instrument. Chemical and physical properties of WSA-650, RSA-650, RSA-

236 500, and silica fume are shown in Table 2. All ash samples (WSA-650, RSA-650, and RSA-500)

237 had similar chemical composition. Silica $\left(\mathrm{SiO}_{2}\right)$ content of silica fume was approximately $10 \%$

238 higher compared to ash samples; however, $\mathrm{CaO}$ content of ash samples was approximately $9 \%$

239 higher than that of silica fume which contains very little $\mathrm{CaO}$. The ash samples had much higher

240 surface area than silica fume. Among the ash samples, WSA-650 had the lowest $\left(65 \mathrm{~m}^{2} / \mathrm{g}\right)$

241 surface area, and RSA-500 had the highest $\left(200 \mathrm{~m}^{2} / \mathrm{g}\right)$ surface area which was more than 20

242 times larger than that of the silica fume. This could be attributed to the internal porosity of ash

243 samples as shown in Fig. 2.

244 The XRD data for WSA-650, RSA-650, RSA-500, and silica fume samples are shown in

245 Fig. 3. WSA-650 showed very low crystalline phases, similar to silica fume. RSA-650- and

246 RSA-500 showed some crystalline quartz. Table 3 shows Rietveld refinement results. The RSA 
247 samples had the lowest amorphous content, whereas the WSA sample was made up of over 99\%

248 amorphous content, practically like silica fume.

\section{3.2. Chappelle test:}

Results from the Chappelle test showed that SCMs used were pozzolanic because the

251 amount of CH fixed by each SCM was higher than $800 \mathrm{mg}$ [25]. Silica fume fixed/consumed

252 more $\mathrm{CH}$ than ash samples, as shown in Fig. 4. Silica fume fixed $18.8 \%$ more $\mathrm{CH}$ than what was

253 fixed by the RSA-650 sample. The high surface area of ash samples did not appear to increase

$254 \mathrm{CH}$ fixation during the Chappelle test. This result is in agreement with what Cordeiro and Sales

255 [25] have shown. This is most likely because the high temperature and alkalinity in the

256 Chappelle test provides only an index of the total potential reactive material in the SCM rather

257 than the reactivity kinetics of the SCM. The accuracy of the Chappelle test in determining the

258 pozzolanic reactivity of materials is also limited because of the extreme conditions in the test and

259 because the pozzolanic reaction in cementitious systems is more complex than that provided by

260 the test solution. This is evidenced by the crystalline quartz results which fixed $202 \mathrm{mg}$ of $\mathrm{CH}$ in

261 the Chappelle test.

\section{3.3. Reaction Kinetics}

263 Silica fume and ash samples increased the heat of hydration produced by cement, as

264 illustrated in Fig. 5. Ash samples (WSA-650, RSA-650 and RSA-500) and silica fume shortened

265 the induction period, possibly because of the high surface area of samples that can act as

266 nucleation sites, thus accelerating the hydration [9] [33]. Peaks from silicate and aluminate

267 hydration were slightly larger for samples containing silica fume than those containing ash

268 samples. However, cement paste samples containing WSA or RSA showed similar total heat of

269 hydration to silica fume containing sample. 
271 kinetics complementary to isothermal calorimetry, shown for the paste samples experiments in

272 Fig. 6. Samples containing SCMs (RSA-650, RSA-500, WSA-650, and silica fume) had higher

273 chemical shrinkage, per gram of dry cement, as compared to control (OPC) samples. However,

274 paste samples containing SCMs showed similar chemical shrinkage to each other.

275 Calcium hydroxide $(\mathrm{CH})$ of cement paste samples at different ages is shown in Fig. 7.

276 The OPC mixture has the highest $\mathrm{CH}$ content as expected. At three and seven days, the $\mathrm{CH}$

277 content of paste samples containing ash samples (OPC+WSA650, OPC+RSA650, and

278 OPC+RSA500) was slightly lower than those containing silica fume, whereas for the rest of the

279 hydration period (28, 91, and 180 days) the $\mathrm{CH}$ content of silica fume containing paste samples

280 was lower than those containing ash samples.

\section{3.4. Compressive strength:}

Compressive strength data for mortar samples is shown in Fig. 8. At a given age, samples

283 containing either RSA or silica fume had higher compressive strength than control (OPC)

284 samples. At a given age, compressive strength of samples containing RSA was similar to those

285 containing silica fume. High surface area of RSA samples did not significantly increase early

286 compressive strength of mortar samples containing RSA since the compressive strength result

287 differences were within the margin of error.

288 3.5. Adsorption of air entraining agents:

289 Results of foam index test are shown in Fig. 9. Results are shown based on non-diluted

290 AEA. As it can be seen, RSA and WSA samples had higher foam index values compared to that

291 of silica fume. At a 5\% replacement level, sample containing RSA-500 required $2.75 \mu 1$ of AEA

292 whereas the sample containing silica fume needed 1.5 $\mu$ l of AEA to form a stable foam layer. 
293 The increased AEA adsorption by WSA and RSA samples could be associated to their higher

294 surface areas than that of the silica fume. As it can be seen in Fig. 2, the high surface area of ash

295 samples is because of their internal porosities. However, AEA requirements of SCMs not only

296 depend on the surface area but also on the amount of SCMs used (Fig. 9). The higher the amount

297 of SCMs, the lower is the AEA requirement per gram of SCMs. Therefore, the surface area of

298 SCM is not the only factor that affects AEA dosage requirement. The extent of pozzolanic

299 reaction could also affect the AEA adsorption in cementitious systems.

300 3.6. Impact of ash samples on retarders:

301 Isothermal heat of hydration of cement paste showed that for the retarder dosage used,

302 samples containing WSA, RSA, or silica fume reduced retardation compared to control samples

303 (OPC). Retarded samples containing 10\% RSA (RSA650 or RSA500) showed similar induction

304 period to the control sample without retarder, as it can be seen in Fig. 10a. Comparing Fig. 10a

305 and Fig. 10b, it can be said that a reduction in SCM content was associated with an increase in

306 retardation. Samples containing 5\% of RSA650 showed a 2.75 hr. retardation while samples

307 without SCM had $5.32 \mathrm{hr}$. retardation. At the retarder dosage used (200ml/100 kg of cement),

308 samples containing silica fume showed higher retardation compared to those containing either

309 WSA650 or RSA (RSA500 and RSA650). This could be attributed to lower surface area of silica

310 fume compared to that of the ash samples.

\section{3.7. Final Discussion:}

312 WSA and RSA showed similar pozzolanic behavior to that of the silica fume. Although

313 SCMs with high surface area are believed to increase early reaction of cementitious systems, the

314 higher surface area of WSA and RSA did not increase the early hydration because paste samples

315 containing WSA and RSA revealed similar induction periods and total heat of hydration when 
316 compared to silica fume. This result could be because surface area of WSA and RSA was not

317 available for C-S-H precipitation. Availability of surface area of ash in cement hydration could

318 be limited by various factors. Ash samples are not spherical and have complex shape and

319 structure [7]. Consequently, dissolution of small amounts of silica from ash may dramatically

320 reduce the surface area. This could mean that the very high surface area provided by RSA and

321 WSA could affect setting by providing additional nucleation sites, but may decrease in

322 effectiveness in increasing hydration with time. It is also possible that availability of surface area

323 is less in WSA and RSA because internal pores can be diffusion controlled. Pozzolanic reactivity

324 of WSA and RSA will also be affected by reactivity of their silica phase. In addition, if carbon

325 and potassium or other impurities precipitate on the surface of ash [3], it could prevent the

326 surface area from participating in the nucleation process of calcium silicate hydrate. Besides

327 limited surface area availability of ash samples for pozzolanic reaction, silica fume could provide

328 enough surface area for the nucleation process. These factors effectively result in similar strength

329 performance for ash samples to silica fume, even though the ash samples have higher surface

330 areas. The surface area did seem to increase the pozzolanic reactivity of the WSA and RSA

331 before 7 days as measured by $\mathrm{CH}$ consumption. The silica fume showed however lower $\mathrm{CH}$

332 content at later ages, possibly owing to the higher amorphous silica content of the silica fume.

333 This higher $\mathrm{CH}$ consumption of the silica fume than the RSA and WSA was not reflected in later

334 age strengths. It is possible that the higher $\mathrm{CH}$ consumption could reduce water absorption or

335 other transport properties, however these measurements were beyond the scope of this study.

336 It was noticed in the mortar experiments that the workability of the mixtures containing

337 RSA and WSA was reduced substantially. This is because of the angular particles and high 
338 internal surface area of the particles that would trap water. Detailed measurements of the

339 workability were however beyond the scope of this study.

340 Larger silicate and aluminate hydration peaks and higher early age ( 3 and 7 days) $\mathrm{CH}$

341 content of paste samples containing silica fume, as compared to those containing WSA or RSA

342 could be attributed to water sorption by ash samples. WSA and RSA could have higher sorption

343 capacity than silica fume because of higher internal porosity and surface area. Sorption of water

344 by WSA and RSA reduces available water for cement reaction, thus reducing $\mathrm{CH}$ content of

345 paste samples. Water encased in pores within ash samples is available for hydration once a

346 demand is presented. Availability of water at later ages could be the cause of high $\mathrm{CH}$ content of

347 samples containing WSA and RSA after 28 days of hydration, as shown in Fig. 7.

348 The analogy of water sorption by WSA and RSA samples could also be applied to

349 chemical admixtures or dissolved Ca. The increase in foam index for samples containing WSA

350 or RSA, as shown in Fig. 9, could be because of adsorption of AEA on the surfaces of WSA and

351 RSA. Besides surface area, it has been postulated that unburned carbon content of SCM can also

352 impact AEA adsorption [10]. However, results revealed that there is no correlation between LOI

353 and foam index, as shown in Fig. 11. The ash sample with the highest surface area had the

354 highest foam index while the silica fume mixture had the lowest surface area and the lowest

355 foam index (Fig. 11). At 10\% cement replacement level, there was a good correlation between

356 surface area and foam index (Fig. 11a). However, at 20\% cement replacement level, the

357 correlation between surface area and foam index became poor (Fig. 11b). Therefore, it can be

358 said that AEA adsorption capacity of SCMs not only depends on their surface areas and LOI, but

359 also on the type of surface area, surface charging, and availability of the surface area for AEA

360 adsorption. 
Several mechanisms have been proposed on the influence of retarders on cement

362 hydration [34]. One mechanism, though, is the adsorption of retarders onto the unhydrated

363 silicates and aluminates surfaces. This reduces the dissolution of silicates and aluminates and

364 lowering nucleation sites for calcium-silicate-hydrate $(\mathrm{C}-\mathrm{S}-\mathrm{H})$ precipitation. Therefore it can be

365 said that the dramatic reduction in retardation in samples containing WSA or RSA, as shown in

366 Fig. 10, is because of adsorption of retarders onto the surface area of ash samples. A small

367 increase in slow-reaction period for samples containing WSA or RSA can be attributed to the

368 adsorption of small amount of chemicals onto the surface of cement grains. Thus, for concrete

369 containing SCM with high surface area, such as WSA and RSA, it is important to adjust the

370 AEA dosage accordingly.

\section{4. Conclusions:}

Influences of dilute acid pretreated wheat straw ash (WSA) and rice straw ash (RSA)

373 prepared at either $650^{\circ} \mathrm{C}$ or $500^{\circ} \mathrm{C}$ in the laboratory on early hydration behavior as well as on

374 chemical admixtures were studied. Results were compared to those of silica fume. Results

375 showed that although WSA and RSA samples had much higher surface area than silica fume,

376 pozzolanic reactivity of all samples was similar. Cement paste samples containing $10 \%$ silica

377 fume showed similar heat of hydration, chemical shrinkage, and calcium hydroxide $(\mathrm{CH})$ content

378 to those containing $10 \%$ WSA or RSA. Additionally, at a given age of hydration, mortar samples

379 containing $10 \%$ silica fume and those containing 10\% RSA had similar compressive strength,

380 showing that the high surface area of WSA and RSA samples had negligible influence on the

381 early pozzolanic reactivity. This shows that it is not just the surface area of amorphous silica but

382 also availability of surface area that can be affected by shape and composition of SCMs that

383 controls early cement reaction. Results suggested that WSA and RSA samples had much higher 
384 adsorption capacity of air entraining agents and retarders compared to silica fume. This was

385 mainly because of high surface area of WSA and RSA. Thus, WSA and RSA could dramatically

386 reduce the effectiveness of these chemical admixtures in concrete.

\section{5. Acknowledgements:}

$388 \quad$ Funding for this study was provided by the National Science Foundation under award \#

389 CMMI-103093. The authors are thankful to Sarah Taylor Lange for her help in performing the

390 Rietveld refinement analysis. Authors are also grateful to Ash Grove Cement Company for 391 determining chemical compositions of samples. Authors are appreciative for W.R. Grace for 392 providing the chemical admixtures.

\section{6. References:}

[1] waob, "World Agricultural Supply and Demand Estimates," United States Department of Agricultural, 2011.

[2] F. Ataie and K. Riding, "Use of bioethanol byproduct for supplementary cementitious material production," Construction and Building Materials, vol. 51, pp. 89-96, 2014.

[3] F. F. Ataie and K. A. Riding, "Thermochemical Pretreatments for Agricultural Residue Ash Production for Concrete," Journal of Materials in Civil Engineering, 2012.

[4] F. F. Ataie and K. A. Riding, "Impact of pretreatments and enzymatic hydrolysis on agricultural residue ash suitability for concrete," Construction and Building Materials, vol. 58, no. 15 , p. 25-30, 2014.

[5] Q. Feng, H. Yamamichi, M. Shoya and S. Sugita, "Study on the pozzolanic properties of rice husk ash by hydrochloric acid pretreatment."," Cement and Concrete Research, vol. 34, 
no. 3, pp. 521-526, 2004.

[6] A. Salas, S. Delvasto, R. M. d. Gutierrez and D. Lange, "Comparison of two processes for treating rice husk ash for use in high performance concrete," Cement and Concrete Research, vol. 39, pp. 773-778, 2009.

[7] N. V. Tuan, G. Ye, K. v. Breugel, A. L. Fraaij and B. D. Dai, "The study of using rice husk ash to produce ultra high performance concrete," Construction and Building Materials, vol. 25, p. 2030-2035, 2011.

[8] S. Wansom, S. Janjaturaphan and S. Sinthupinyo, "Characterizing pozzolanic activity of rice husk ash by impendence spectroscopy," Cement and Concrete Research, vol. 40, no. 12, pp. 1714-1722, 2010.

[9] B. Lothenbach, K. Scrivener and R. Hooton, "Supplementary Cementitious Materials," Cement and Concrete Research, vol. 41, p. 1244-1256, 2011.

[10] M. T. Ley, N. J. Harris, K. J. Folliard and K. C. Hover, "Investigation of Air-Entraining Admixture Dosage in Fly Ash Concrete," ACI Materials Journal, vol. 105, no. 5, pp. 494498, 2008.

[11] M. Mazloom, A. Ramezanianpour and J. Brooks, "Effect of silica fume on mechanical properties of high-strength concrete," Cement and Concrete Composites, vol. 26, no. 4, p. 347-357, 2004.

[12] C. Park, M. Noh and T. Park, "Rheological properties of cementitious materials containing mineral admixtures," Cement and Concrete Research, vol. 35, no. 5, p. 842-849, 2005.

[13] R. Largent, "Estimation de l'activite pouzzolanique," Bull Liaison Lab Pont, Pont Chaussee, vol. 93, pp. 61-65, 1978. 
[14] A. Standard, "Standard Specification for Portalnd Cement," ASTM International, West Conshohocken, PA, 2009.

[15] A. Standard, "C778-12 Standard Specification for Standard Sand," ASTM International, West Conshohocken, PA, 2012.

[16] J. Tangpagasit, R. Cheerarot, C. Jaturapitakkul and K. Kiattikomol, "Packing effect and pozzolanic reaction of fly ash in mortar," Cement and Concrete Research, vol. 35, pp. 1145$1151,2005$.

[17] H. Rietveld, "Line profiles of neutron powder-diffraction peaks for structure refinement," Acta Crystallographica, vol. 22, pp. 151-152., 1967.

[18] H. Rietveld, "A profile refinement method for nuclear and magnetic structures," Journal of Applied Crystallography, vol. 2, pp. 65-71, 1969.

[19] R. Chancey, P. Stutzman, M. Juenger and D. Fowler, "Comprehensive phase characterization of crystalline and amorphous phases of a Class F fly ash," vol. 40, pp. 146$156,2010$.

[20] B. Toby, "R-factors in Rietveld analysis: How good is good enough?," Powder Diffraction, vol. 21, no. 1, pp. 67-70, 2006.

[21] W. I. F. David, "Powder Diffraction:Least-Squares and Beyond," J. Res. Natl. Inst. Stand. Technol., vol. 109, pp. 107-123, 2004.

[22] S. Taylor-Lange, K. A. Riding and M. C. Juenger, "Increasing the reactivity of metakaolincement blends using zinc oxide," Cement \& Concrete Composites, vol. 34, p. 835-847, 2012.

[23] S. Antiohos, V. Papadakis, E. Chaniotakis and S. Tsimas, "Improving the performance of 
ternary blended cements by mixing different types of fly ashes," Cement and Concrete Research, vol. 37, no. 6, p. 877-885, 2007.

[24] V. Kocaba, E. Gallucci and K. L. Scrivener, "Methods for determination of degree of reaction of slag in blended cement pastes," Cement and Concrete Research, vol. 42, no. 3, p. $511-525,2012$.

[25] Cordeiro, G. C. and C. P. Sales, "Pozzolanic activity of elephant grass ash and its influence on the mechanical properties of concrete," Cement and Concrete Composites, vol. 55, p. 331-336, 2015.

[26] G. Cordeiro, T. R. Filho, L. Tavares and E. Fairbairn, "Pozzolanic activity and filler effect of sugar cane bagasse ash in Portland cement and lime mortars," Cement and Concrete Composites, vol. 30, no. 5, p. 410-418, 2008.

[27] K. Riding, D. Silva and K. Scrivener, "Early age strength of blend cement systems by CaCl2 and diethanol-isopropanolmine," Cement and Concrete Research, vol. 40, no. 6, pp. 935946, 2010.

[28] N. V. Tuan, G. Ye, K. v. Breugel and O. Copuroglu, "Hydration and microstructure of ultra high performance concrete incorporating rice husk ash," Cement and Concrete Research, vol. 41, p. 1104-1111, 2011.

[29] S. Bishnoi, "Automated Chemical Shrinkage Test and Shrinkage Suite Software," 2009.

[30] A. Standard, "ASTM C109-Standard Test Method for Compressive Strength of Hydraulic Cement Mortars," ASTM International, West Conshohocken, PA, 2008.

[31] I. Kulaots, A. Hsu, R. H. Hurt and E. M. Suuberg, "Size distribution of unburned carbon in coal fly ash and its implications," Fuel, vol. 83, pp. 223-230, 2004. 
[32] A. Standard, "D2419-09- Standard Test Method for Sand Equivalent Value of Soils and Fine Aggregate," ASTM International, West Conshohocken, PA, 2009.

[33] K. Scrivener and A. Nonat, "Hydration of cementitious materials, present and future," Cement and Concrete Research, vol. 41, no. 7, pp. 651-665, 2011.

[34] J. Cheung, A. Jeknavorian, A. Roberts and D. Silva, "Impact of admixtures on the hydration kinetics of Portland cement," Cement and Concrete Research, vol. 41, p. 1289-1309, 2011. 


\section{List of tables:}

Table 1: Cement properties

\begin{tabular}{cccc}
\hline \multicolumn{2}{c}{$\begin{array}{c}\text { Chemical } \\
\text { Composition (\%) }\end{array}$} & \multicolumn{2}{c}{$\begin{array}{c}\text { Bogue compounds } \\
(\%)\end{array}$} \\
\hline $\mathrm{SiO} 2$ & 19.36 & $\mathrm{C} 3 \mathrm{~S}$ & 62.76 \\
$\mathrm{~A} 2 \mathrm{O} 3$ & 5.13 & $\mathrm{C} 2 \mathrm{~S}$ & 8.16 \\
$\mathrm{Fe} 2 \mathrm{O} 3$ & 2.53 & $\mathrm{C} 3 \mathrm{~A}$ & 9.31 \\
$\mathrm{CaO}$ & 63.17 & $\mathrm{C} 4 \mathrm{AF}$ & 7.70 \\
$\mathrm{MgO}$ & 1.03 & & \\
$\mathrm{~K} 2 \mathrm{O}$ & 0.88 & & \\
$\mathrm{Na} 2 \mathrm{O}$ & 0.086 & & \\
$\mathrm{SO} 3$ & 3.22 & & \\
\hline
\end{tabular}

Table 2: SCM properties

\begin{tabular}{|c|c|c|c|c|c|c|c|c|c|}
\hline \multirow{2}{*}{ Sample ID } & \multicolumn{7}{|c|}{ Chemical compositions (\%) } & \multirow{2}{*}{$\begin{array}{l}\text { BET surface } \\
\text { area }\left(\mathrm{m}^{2} / \mathrm{g}\right)\end{array}$} & \multirow{2}{*}{$\begin{array}{l}\text { LOI } \\
(\%)\end{array}$} \\
\hline & $\mathrm{SiO}_{2}$ & $\mathrm{Al}_{2} \mathrm{O}_{3}$ & $\mathrm{Fe}_{2} \mathrm{O}_{3}$ & $\mathrm{CaO}$ & $\mathrm{MgO}$ & $\mathrm{K}_{2} \mathrm{O}$ & $\mathrm{Na}_{2} \mathrm{O}$ & & \\
\hline WSA650 & 86.5 & 0.28 & 1.13 & 9.73 & 0.78 & 1.54 & 0.1 & 65 & 1.2 \\
\hline RSA650 & 88.2 & 0.47 & 0.74 & 9.48 & 0.56 & 0.31 & 0.17 & 134 & 0.8 \\
\hline RSA500 & 85.7 & 1.4 & 1.02 & 10.73 & 0.6 & 0.34 & 0.23 & 200 & 2.2 \\
\hline Silica Fume (SF) & 96.96 & 0.13 & 0.05 & 0.43 & 0.96 & 0.38 & 0.08 & 8.9 & 1.6 \\
\hline
\end{tabular}

Table 3: Rietveld refinement data

\begin{tabular}{ccccc}
\hline Minerals & RSA-650 & RSA-500 & WSA-650 & SF \\
\hline Quartz (mass \%) & 4.2 & 11.8 & 0.7 & 0.1 \\
Amorphous (mass \%) & 95.8 & 88.2 & 99.3 & 99.9 \\
& & & & \\
\hline
\end{tabular}




\section{List of figures:}

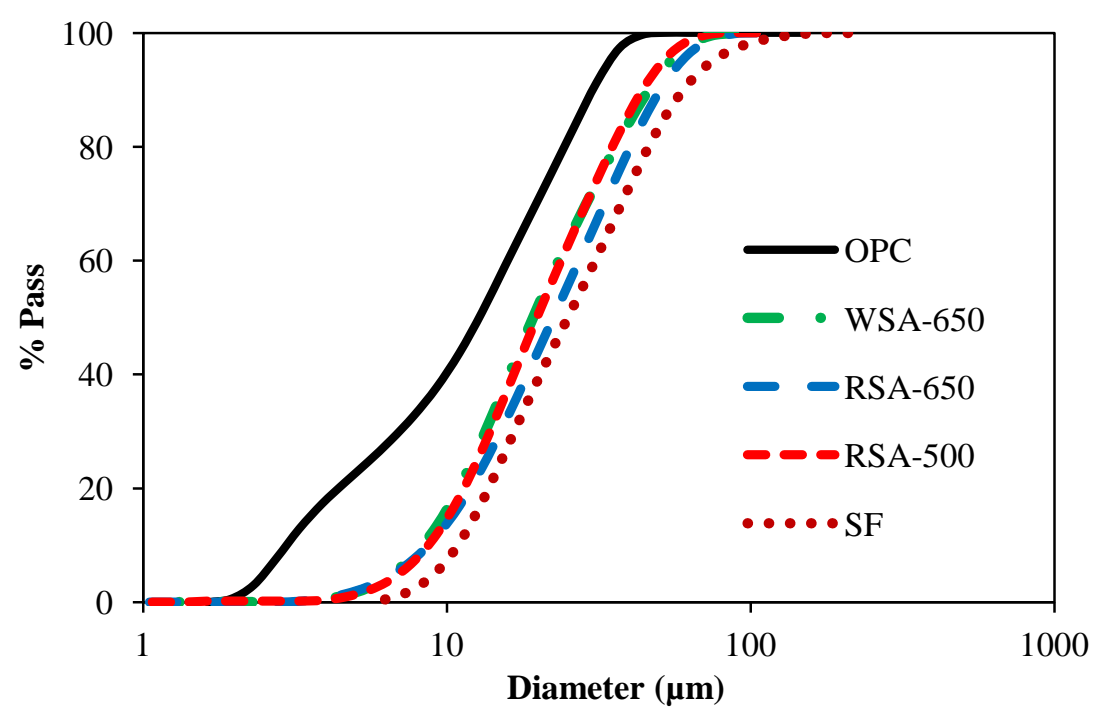

Fig. 1: Particle size distribution

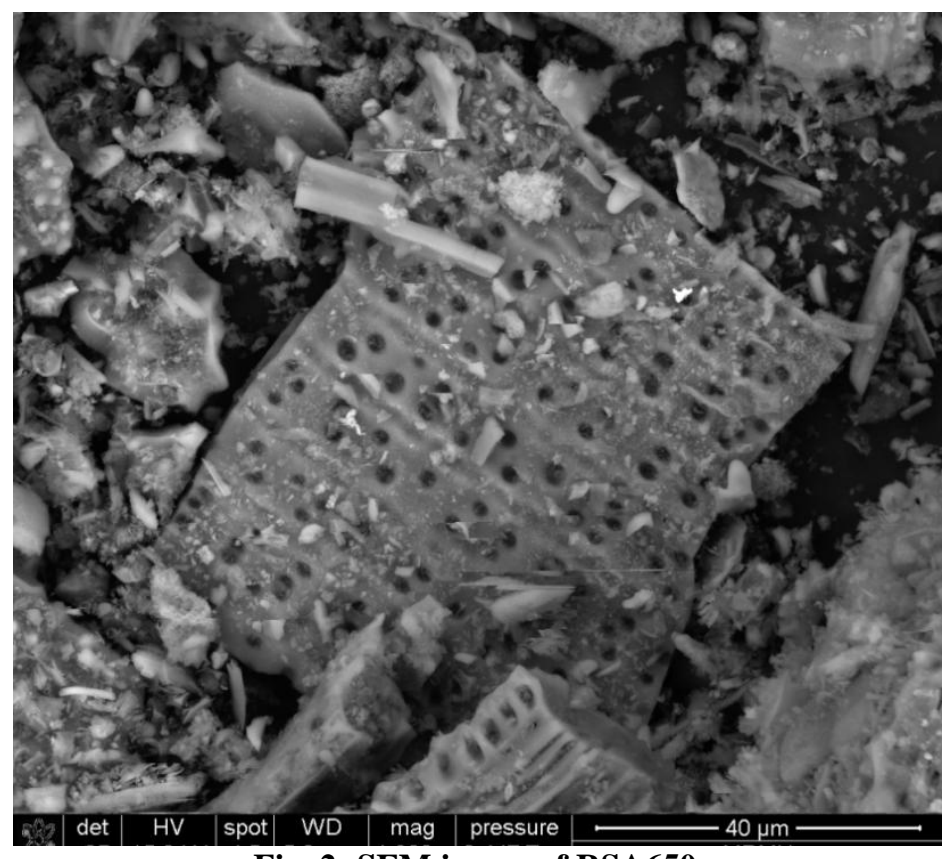

Fig. 2: SEM image of RSA650 


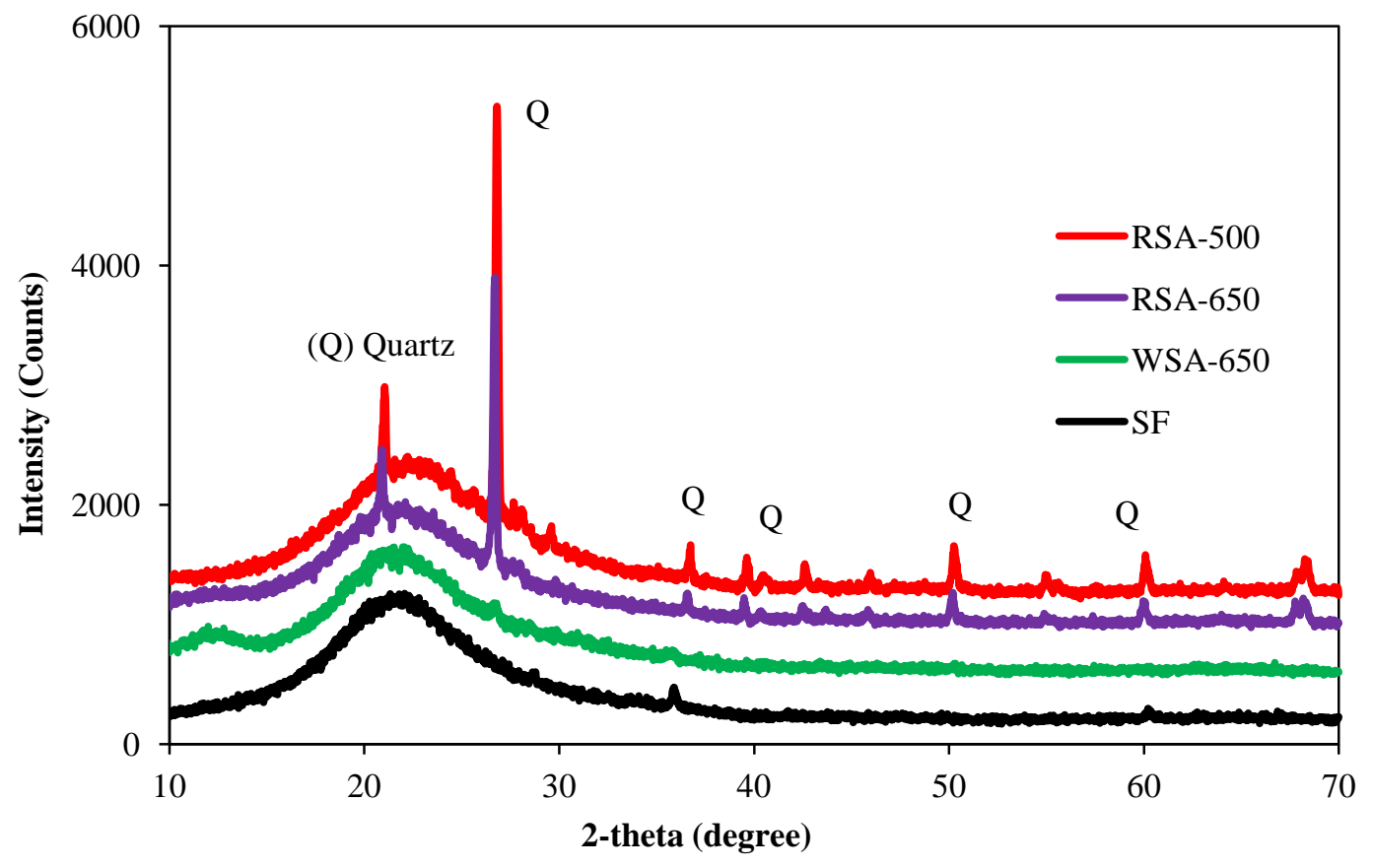

Fig. 3: XRD plots for WSA, RSA, and SF

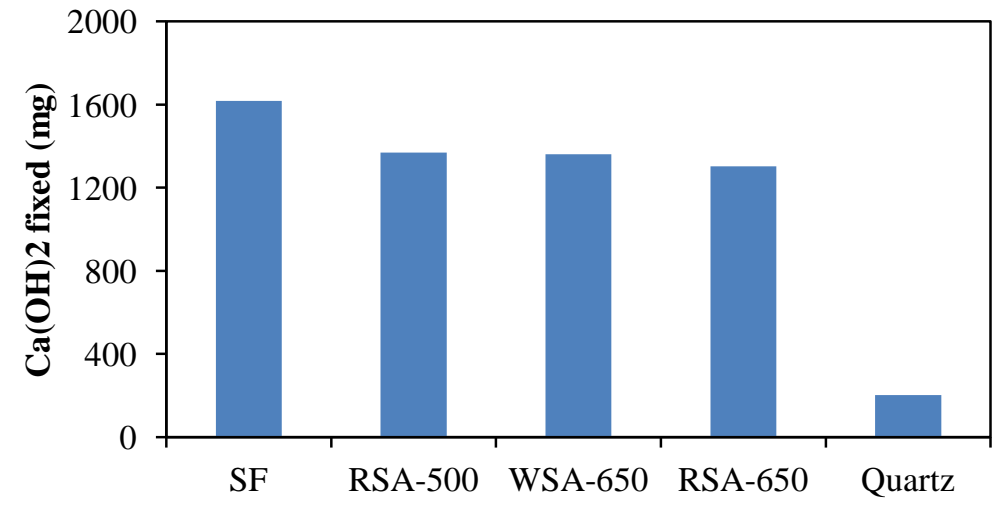

Fig. 4: Chappelle test results 

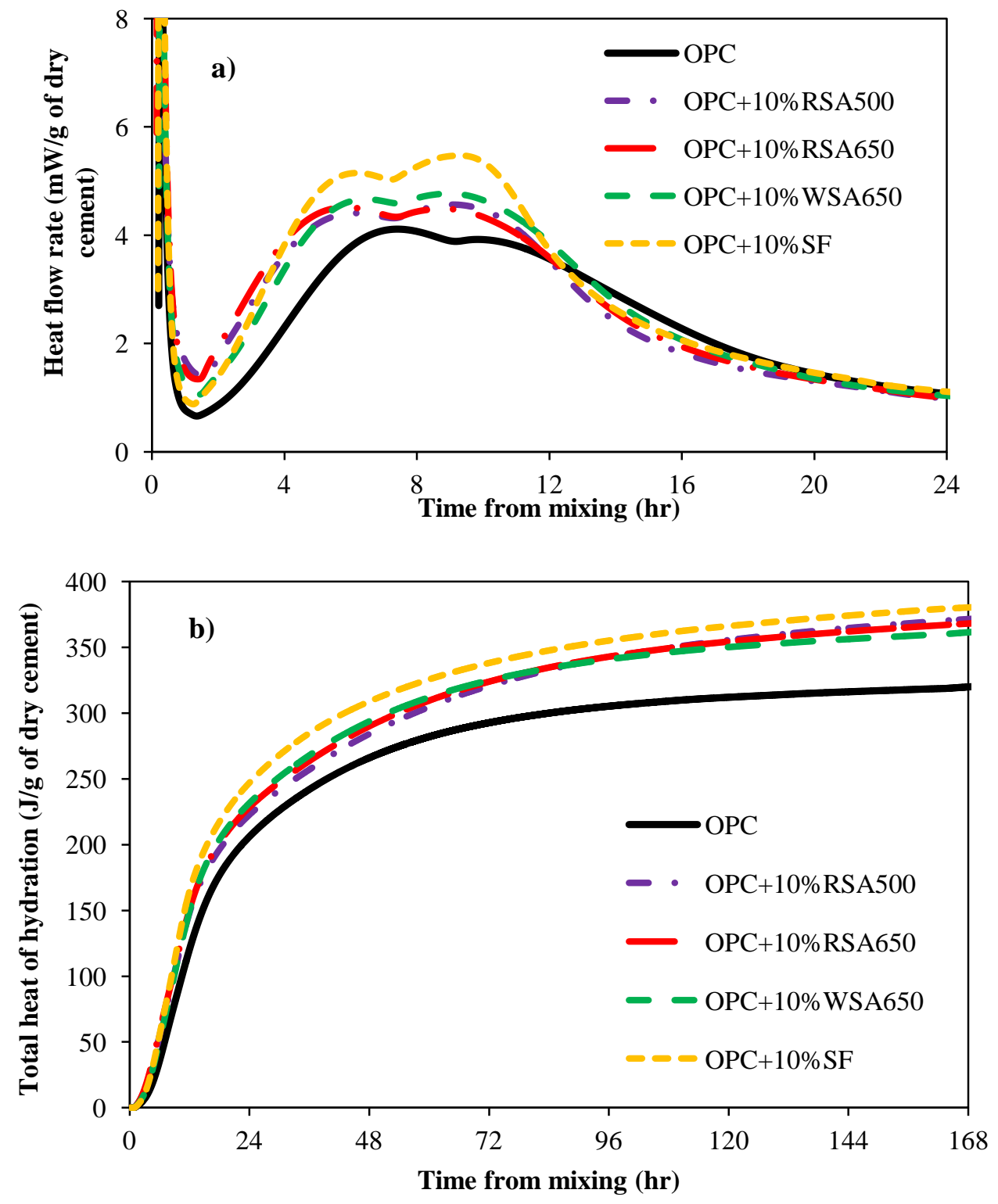

Fig. 5: Heat of hydration of paste samples: a) heat flow rate, b) cumulative heat of hydration 


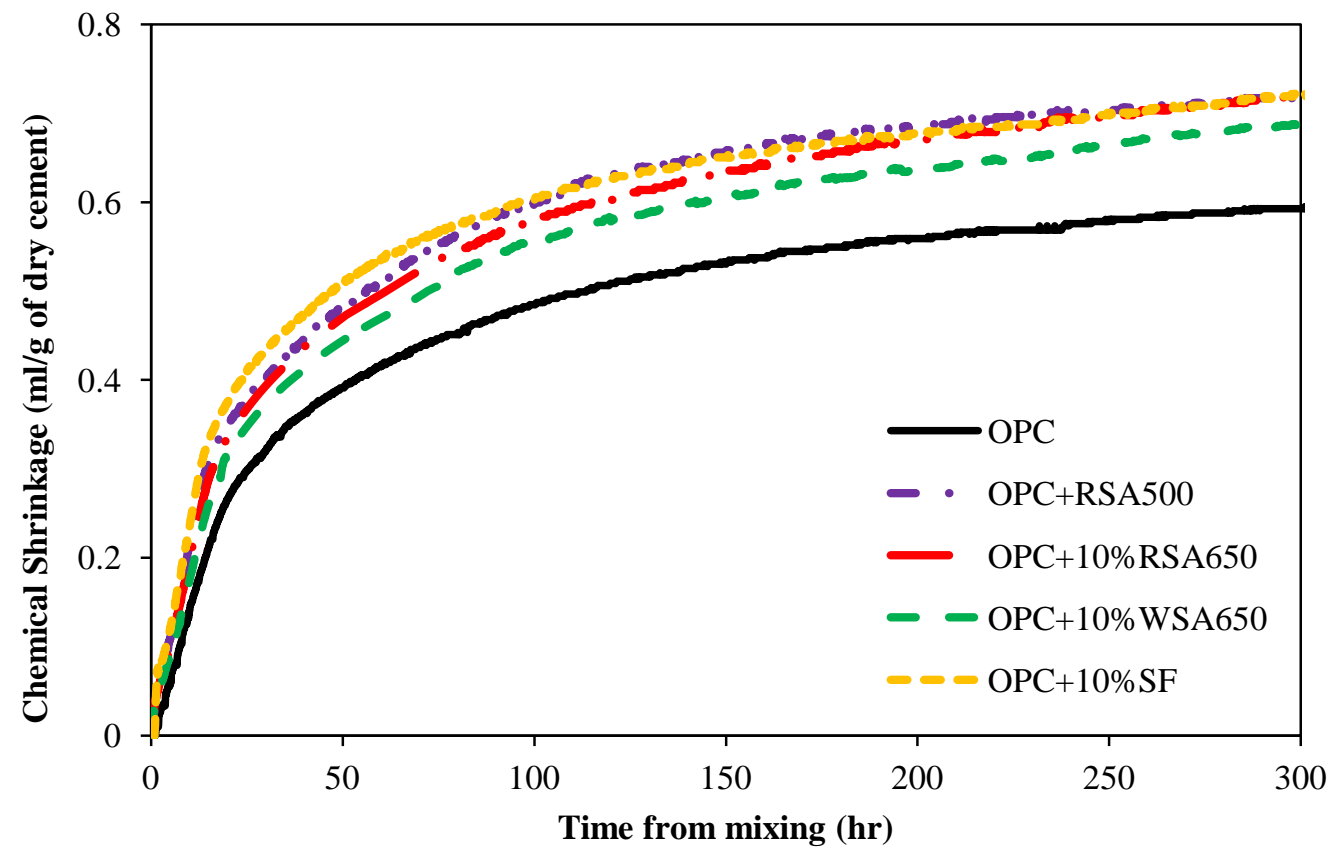

Fig. 6: Chemical shrinkage of paste samples

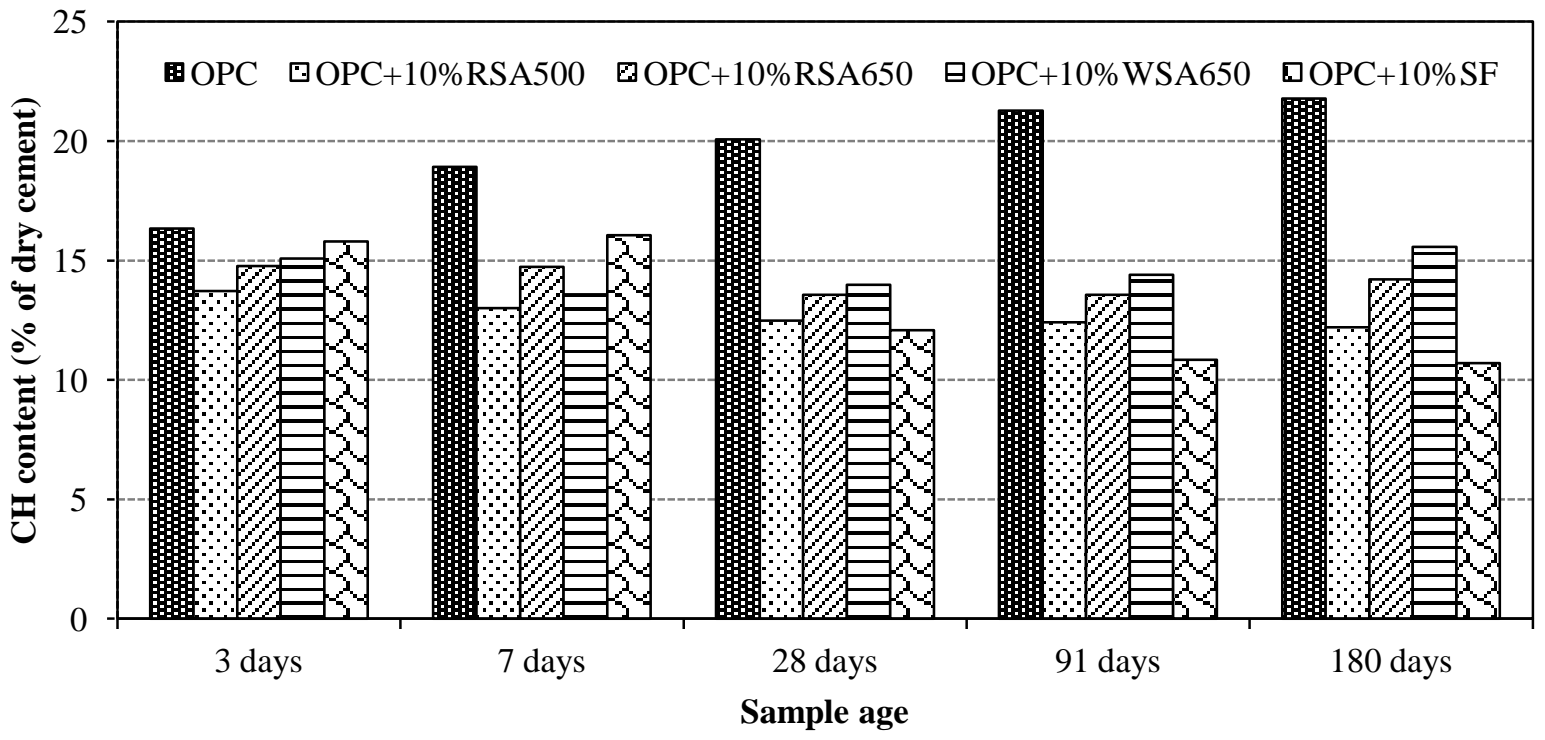

Fig. 7: Calcium hydroxide $(\mathrm{CH})$ content of cement paste samples (results were obtained from TGA data) 


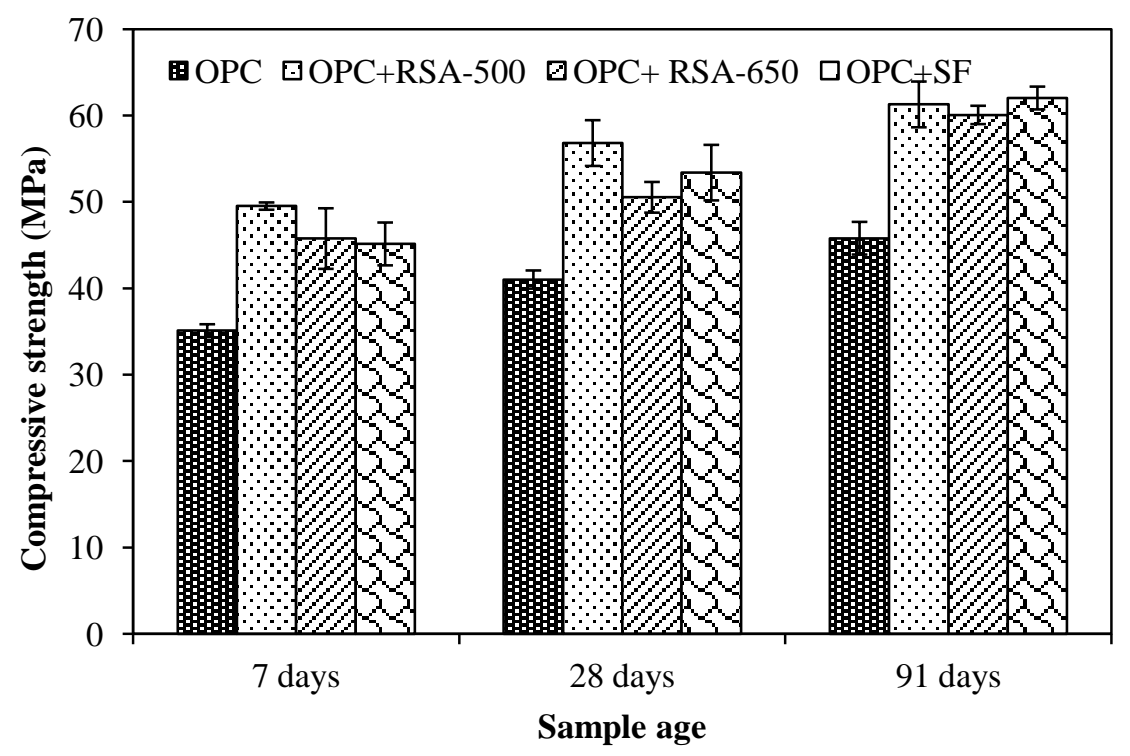

Fig. 8: Mortar cube compressive strength

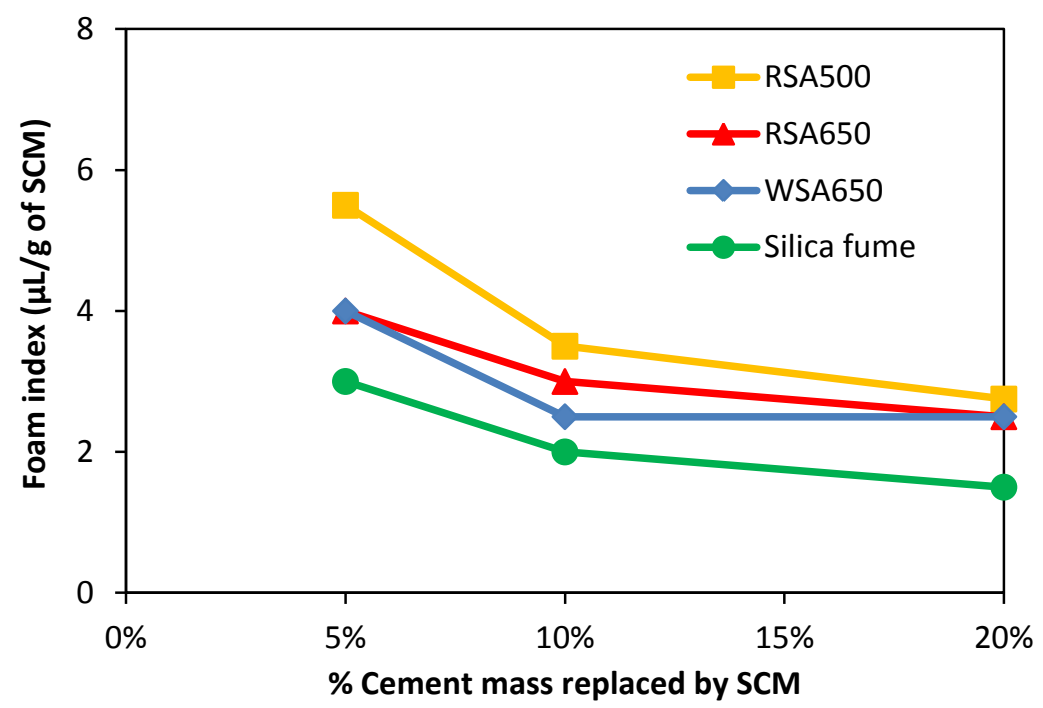

Fig. 9: Foam index values for WSA, RSA, and silica fume 

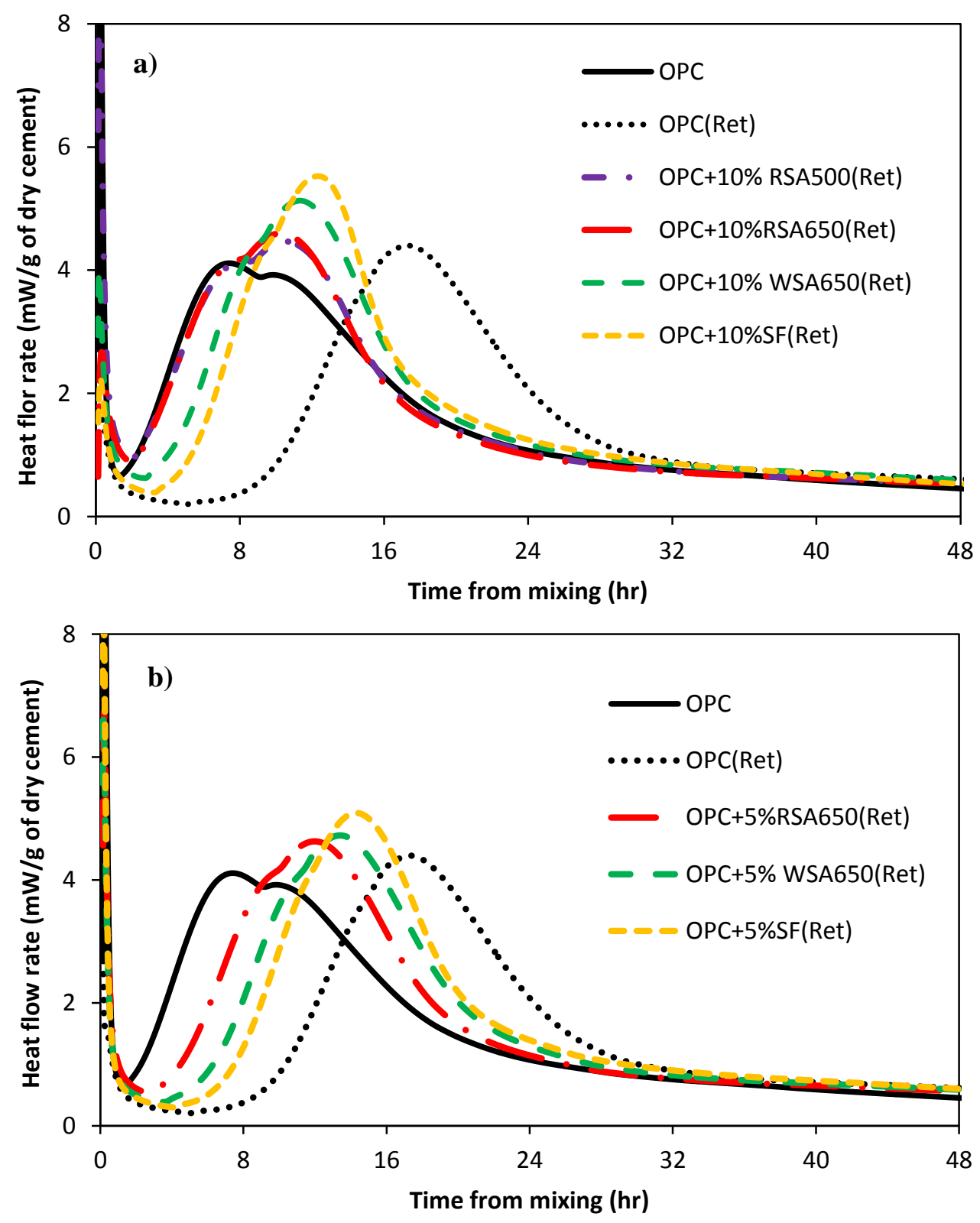

Fig. 10: Retardation of samples containing a) $10 \%$ SCM, and b) $5 \%$ SCM 

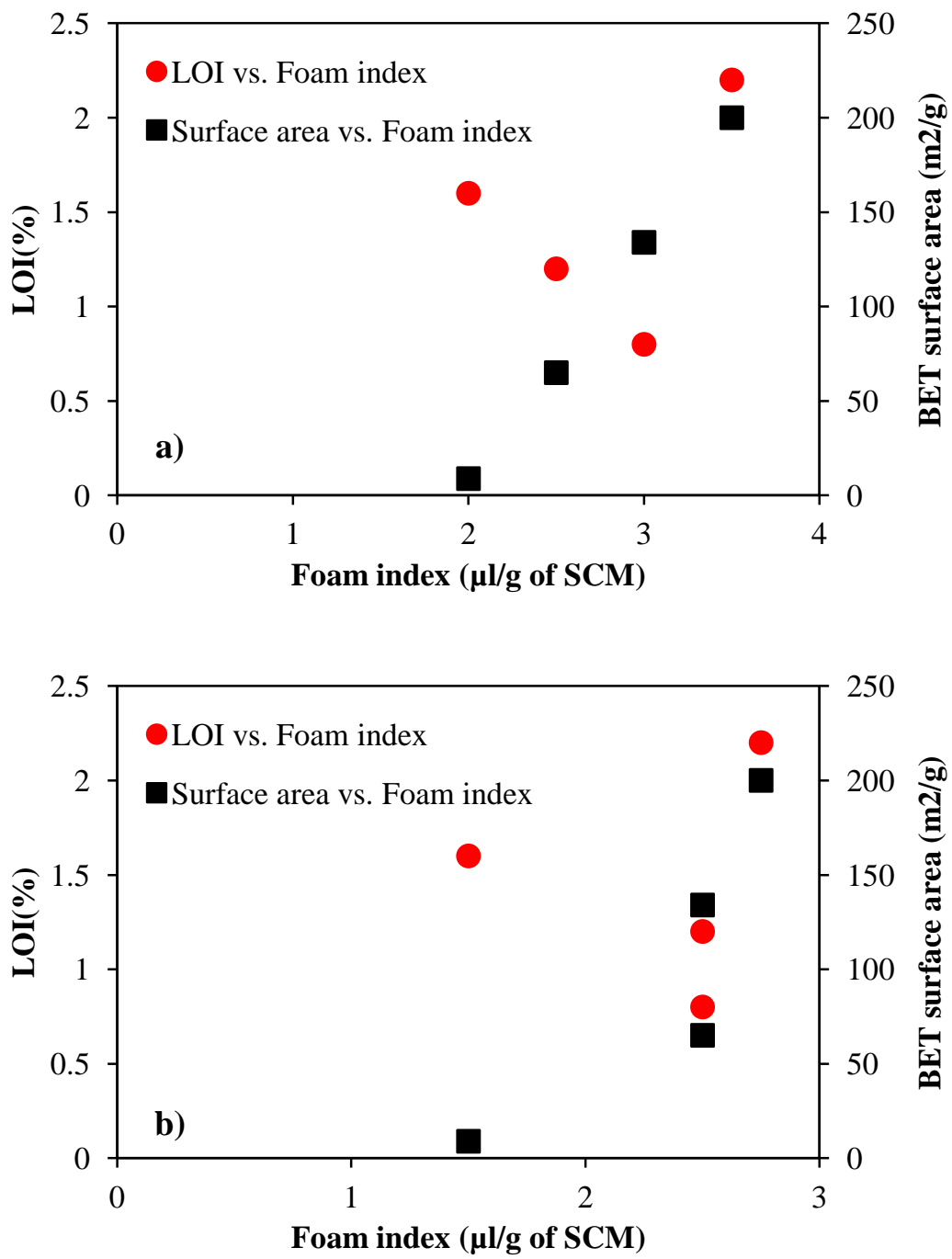

Fig. 11: Correlation between surface area, LOI, and foam index. a) at $10 \%$ cement replacement level; b) at $20 \%$ cement replacement level 